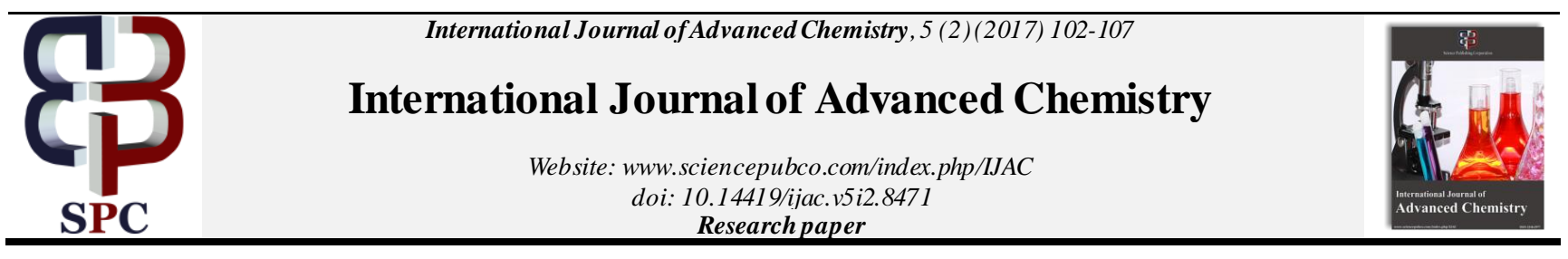

\title{
Di- and tetranuclear gadolinium (III) complexes of 2-hydroxypropane-1,2,3-tricarboxylic acid and 1,2,2-trimethylcyclopentane-1,3-dicarboxylic acid : identification and characterization
}

\author{
M. Riri ${ }^{1 *}$,M. Hor ${ }^{1}$, T. Eljaddi ${ }^{1,2}$, A. Benajjar 1,3, F. Hadhoudi ${ }^{1}$, S. Ezzemouri ${ }^{1}$, M. Hlaibi ${ }^{1,2}$ \\ ${ }^{1}$ Laboratory of Material - Material Interaction and Processes Membrane (I3MP), Hassan II University, Faculty of Sciences \\ Ain Chock, BP 5366, Maârif, Casablanca, Morocco \\ ${ }^{2}$ Laboratoire des Polymères, Biopolymères, Surfaces, UMR 6270 du CNRS. Université de Rouen, Faculté des Sciences, \\ F-76821 Mont-Saint-Aignan, France \\ ${ }^{3}$ High Engineering School of Information, Management and Civil Engineering, Casablanca, Morocco \\ *Corresponding authorE-mail: medriri@gmail.com
}

\begin{abstract}
Our studying involved, Identification and characterization of two novel gadolinium complexes with 2-hydroxypropane-1,2,3tricarboxylic acid (citric acid) noted $\mathrm{H}_{3} \mathrm{~L}$ and 1,2,2-trimethylcyclopentane-1, 3-dicarboxylic acid (camphoric acid) noted $\mathrm{H}_{2} \mathrm{~L}$ in aqueous solution and in $\mathrm{pH}$ range 5,5-7,5. These acids containing the donor atoms (oxy gen of $\mathrm{OH}$ and $\mathrm{COOH}$ ), the formatted complexes are colorless and have no absorption band UV-visible. So, to determine the composition and stabilities of these complexes in solution, we have used an analytical technique called «Indirect Photometry Detection (IPD)» have identified multi-nuclear and multi-dentate complexes studied in this work. Giving for these colorless complexes with a mole ratio (M:L): (4:2) for Gd (III)-Citric acid and (2:2) Gd (III)-Camphoric acid. In addition, we have shown that the compositions and stabilities constant of these comple xes are depended on the acidity of the medium.
\end{abstract}

Keywords: Citric and Camphoric Acid; Coloress Complexes; IndirectPhotometry Detection; Gadolinium Complexes; Stability of Contrast Agents.

\section{Introduction}

The gadolinium ion is highly toxic in its hydrated form [Gd $\left.\left(\mathrm{H}_{2} \mathrm{O}\right)_{8}\right]^{3+}$, Its complexation with an organic ligand reduces this toxicity for IRM or other medical using. This complexation should be administered in the form thermodynamically stable (Reimer et al. 1996 p.36). The solution consists of enclosing the gadolinium ion $\mathrm{Gd}(\mathrm{III})$ in the organic ligands to form $\mathrm{Gd}$-Ligands complexes non toxic and very stable in the human body (Thunus \& L, Lejeune 1999 p.125, Guo-Ping et al. 2005 p 11, Yoshimasa et al. 2016 p. 148, Sofía \& Martín 2017 p. 31). The most widely ligands used are polyaminocarboxylates and their derivatives. In this work, we have studied the formation of colorless gadolinium complexes with some linear ligands in dilute solutions (citric and camphoric acid). To study of these colorless complexes, we developed a new analytical technique for determining the compositions and stabilities of some colorless complexes, which have no absorption band UV-visible. This technique is the Indirect Photometry Detection (IPD), based on competitive reactions by ligand-ligand exchange.

$\mathrm{Gd}-\mathrm{L}_{\mathrm{n}}+\mathrm{n}^{\prime} \mathrm{L}^{\prime} \longleftrightarrow \mathrm{Gd}^{-} \mathrm{L}_{\mathrm{n}^{\prime}}+\mathrm{nL}$

Color reagent Ligand Colorless Complex Auxiliary Ligand
This method is simple, reproducible, effective and applicable to very dilute solutions. Thus, the importance of IPD technique was also revealed by its adaptation to other techniques of separation, determination and characterization, such as liquid chromatography (Rocklin 1991 p. 175, Verchere \&, Dona 1992 p. 437), capillary electrophoresis (Morin et al. 1994 p. 178), continuous flow analysis (FIA) (Ramshing et al. 1980 p. 165) and Ramn, IR, RMN spectroscopies (Hlaibi et al. 2009 p. 310, Riri et al. 2014 p. 130). Some studies show that this technique is very effective for identifying some color less gadolinium complexes (Riri et al. 2011 p. 303, Riri et al. 2013 p. 49) and tungstate complexes of sugars and organic ligands (Millan et al. 1995 p. 2334, Riri et al. 2014 p. 130). The detection or monitoring of certain diseases sometimes requires injection gadolinium complexes because of the interesting electronic and magnetic properties of this ion (Hiroyuki et al. $2002 \mathrm{p}$. 1119 , Nonat et al. 2006 p. 7133). The most contrast agents used in MRI are complexes of amino acids and carboxylic acids with some lanthanides (Anelli et al. 1997 p. 125, Angela \& Wing-Tak 2008 p. 1323). Currently, most contrast agents used in MRI are complexes of gadolinium-DTPA, gadolinium-BOPTA, gadolinium-DOTA (Anelli et al. 1997 p. 125, Angela \& Wing-Tak 2008 p. 1323 , Nwe et al. 2010 p. 5925 , Moller \& Sasu 2010 p. 125 , Jonathan et al. 2010 p. 10056) and its analogs, which are modified to enhance the contrast effect on fabric (Tsan-Hwang et al. $2001 \mathrm{p}$. 3357, Moller et al. 2011 p. 140, Lee et al. 2011 p. 83). Other studies have shown that gadolinium complexes of coumarin-3- 
carboxylic acid (2-oxo-2H-chromene-3-carboxylic acid) and its derivatives have very important pharmacological properties (Kostova et al. 2007 p. 8, Yue et al. 2017 p. 5700). In this work, investigations by indirect photometry detection (IPD) were carried out to study the interaction of the trivalent gadolinium ions, with conjugate base of citric and camphoric acid, detecting the majority of colorless complexes formed in solution and determining their compositions and stabilities constant $\left(\log K_{x y z}\right)$. Other studies are interested to studying the stabilities of camphoric acid (Huijie et al. 2015 p. 135, Elisa et al. 2017p. 147) and citric acid (Xuefei et al. 2017 p. 103, Soo et al. 2017 in press) complexes with the formation of polymers or organometallic complexes. The acidity constants and semi developed form of citric and camphoric acid are noted in the Table 1 (Bjerrum 1958, Serjeant \& Dempsey 1979).

Table 1: Some Characteristics of Acids Studied

\begin{tabular}{llll}
\hline Acid & Chemical formula & $\mathrm{pKa}_{1}$ & $\mathrm{pKa}$ \\
\hline Citric $\left(\mathrm{H}_{3} \mathrm{~L}\right)$ & $\mathrm{HOOC}-\mathrm{CH}_{2}-(\mathrm{HOOC}) \mathrm{C}(\mathrm{OH})-\mathrm{CH}_{2}-\mathrm{COOH}$ & \\
Camphoric $\left(\mathrm{H}_{2} \mathrm{~L}\right)$ & & &
\end{tabular}

\section{Experimental section}

\subsection{Chemicals}

Citric acid, Camphoric acid, $\mathrm{NaOH}, \mathrm{HCl}$, Chrome Azurol S ( $\mathrm{H}_{4} \mathrm{Ch}$ ), Gagoliunium nitrate $\left(\mathrm{Gd}\left(\mathrm{NO}_{3}\right)_{3} \cdot 6 \mathrm{H}_{2} \mathrm{O}\right)$ and other chemicals were commercial products (Aldrich, Prolabo,...) of the purest available and analytical grade, used as received.

\subsection{Indirect photometric detection}

Standard Helios $\gamma$ UV-visible spectrometer controlled by Vision 32 software was used for spectrometric measurements, using quartz cells of optical path length $l=1 \mathrm{~cm}$. The absorption measurements have been performed at room temperature and at wavelength $\lambda_{\max }=545 \mathrm{~nm}$. Stock solutions of $\mathrm{Gd}$ (III) nitrate and Chrome Azurol S, were prepared with concentrations respectively $10^{-2} \mathrm{M}$ and $10^{-3} \mathrm{M}$. In a typical experiment, a solution $(v=50 \mathrm{~mL})$ of the colored sacrificial complex ( $\mathrm{Gd}-\mathrm{H}_{4} \mathrm{Ch}$ ) was prepared $\left(\left[\mathrm{Gd}^{3+}\right] /\left[\mathrm{H}_{4} \mathrm{Ch}\right]=1.5\right)$, using it as a buffer of MESH $(0.1 \mathrm{M})$ [2-(N-morpholino) sulfonic ethane acid]. The initial solution also contained a calculated amount of $1 \mathrm{M}(\mathrm{NaOH})$ in order to obtain the desired $\mathrm{pH}$ value $(\mathrm{pKa}(\mathrm{MESH})=6.2$, experimental $\mathrm{pH}$ range (5.50-7.50). $\mathrm{pH}$ values are measured with a microprocessor $\mathrm{pH}$ meter HANNA 210 equipped with a combined electrode glass and calibrated with commercial buffers $(\mathrm{pH} 4.00$ and 7.00). Then aliquots $(v=0.100-0.200 \mathrm{~mL})$ of an aqueous solution of the $\mathrm{H}_{3} \mathrm{~L}$ and $\mathrm{H}_{2} \mathrm{~L}\left(C_{L}=1 \mathrm{~g} / \mathrm{L}\right.$ and $C_{L}=10 \mathrm{~g} / \mathrm{L}$ respectively $)$ was added, using a Gilson micropipet of $0.2 \mathrm{ml}$. After each addition, the resulting solution was left at least $2 \mathrm{~min}$ in order to reach equilibrium (and thus a constant absorption value). Addition was repeated until a maximum volume of $6 \mathrm{ml}$ of the ligand's solution was added. The change in the total volume was neglected. For fixed $\mathrm{pH}$ environments, the apparent formation constants $\log K{ }_{x y z}$ was calculated from the equilibrium of the reaction of formation of these complexes. The absorption values for the undissociated $\left(\mathrm{A}_{\mathrm{F}}\right)$ and the totally dissociated $\left(\mathrm{A}_{\mathrm{I}}\right)$, sacrificial complex $\left(\mathrm{Gd}-\mathrm{H}_{4} \mathrm{Ch}\right)$, are used as determined in experiments using pure Chrome Azurol $\mathrm{S}$, and an excess of Gadolinium(III) (performed at $\mathrm{pH}$ intervals of 0.25). Assuming various integers for the Gadolinium and organic acid's stoichiometry, a formation constant is calculated for each added amount of ligands and corresponding absorption value. The results are rejected when a systematic variation of $\log K_{x y z}$ z occurs with increasing added-up amount of ligands or when individual values of $\log K{ }_{x y z}$ differed from the mean value by more than $2 \%$.

\section{Results and discussion}

\subsection{Indirect photometric detection study: expression of the stability constant of complexes Gd-ligands}

The complexation reaction of gadolinium ions with acids studied in this work, given by general reaction (I):

$$
x G d^{3+}+y L^{n-}+z H^{+} \rightleftarrows(x, y, z)+n H_{2} \mathrm{O}
$$

- $\mathrm{L}^{\mathrm{n}-}$ is ligand (acid) $\left(\mathrm{n}=3\right.$ for $\mathrm{H}_{3} \mathrm{~L}$ and $\mathrm{n}=2$ for $\left.\mathrm{H}_{2} \mathrm{~L}\right)$.

- We noted $(\mathrm{x}, \mathrm{y}, \mathrm{z})$ to simplify the writing of complex formed.

- $\mathrm{x}, \mathrm{y}$ and $\mathrm{z}$ are, respectively, the stoichiometric coefficients relating to the $\mathrm{Gd}^{3+}$ ion, acid studied in its basic form and the number of protons $\mathrm{H}^{+}$involved in complexation reaction.

The formation constant $K_{x z}$ (or stability constant $\beta_{x y z}$ ) of the complexes formed defined by equation (1):

$K_{x y z}=[(x, y, z)] /\left(\left[G d^{3+}\right]^{c} \cdot\left[L^{n-}\right] \cdot\left[H^{+}\right]\right)$

Additionally, a conditional constant $K_{x y z}^{\prime}$ is defined in case of constant $\mathrm{pH}$ value (buffered solution):

$K_{x y z}^{\cdot}=[(x, y, z)] /\left(\left[G d^{3+}\right] \cdot\left(\mathrm{C}_{L}\right)^{y}\right)$

3.1.1. Expression of stability constant $\log K_{x y z}$ of complex Gd$\mathrm{H}_{2} \mathrm{~L}$

Where $\mathrm{C}_{\mathrm{L}}$ represents the analytical concentration of the uncomplexed ligand, therefore, we have for $\mathrm{H}_{2} \mathrm{~L} C_{L}=\left[L^{2-}\right]$ in our $\mathrm{pH}$ range because $\mathrm{pH}>\mathrm{pK}_{\mathrm{a} 2}$ of this acid. Using this equality and $\mathrm{Eq}$. (1) can be written as:

$K_{x y z}^{\prime}=[(x, y, z)] /\left(\left[G d^{3+}\right]^{c} \cdot\left[L^{2-}\right]\right)$

$K_{x y z}^{\prime}=K_{x y 2} \cdot\left[H^{+}\right]$

The formation constant $\mathrm{K}_{\mathrm{xyz}}$ and the apparent constant of this complex defined by equation (5): $\log K_{x y z}=\log K_{x y z}^{\prime}+z \cdot p H$

\subsubsection{Expression of stability constant $\log K x y z$ of complex Gd-} $\mathrm{H}_{3} \mathrm{~L}$

The chemical equilibrium and acidity constant of citric acid $\left(\mathrm{H}_{3} \mathrm{~L}\right)$ are: 


$$
\begin{aligned}
& \mathrm{H}_{3} \mathrm{~L} \longleftrightarrow \mathrm{H}_{2} \mathrm{~L}+\mathrm{H}^{+} \mathrm{K}_{\mathrm{a} 1}=7.41 \times 10^{-4} \quad, \quad K_{a 1} \\
& \mathrm{H}_{2} \mathrm{~L}^{-} \longleftrightarrow \mathrm{HL}^{2-}+\mathrm{H}^{+} \mathrm{K}_{\mathrm{a} 2}=1.74 \times 10^{-5} \quad, \quad K_{a 2} \\
& \mathrm{HL}^{2-} \longmapsto \mathrm{L}_{3}^{-}+\mathrm{H}^{+} \mathrm{K}_{\mathrm{a} 3}=3.16 \times 10^{-7} \quad, \quad K_{a 3} \\
& K_{a 1}=\frac{\left[H_{2} L^{-} I H^{+}\right]}{\left[H_{3} L\right]}, K_{a 2}=\frac{\left[H_{2} L^{2-} I H^{+}\right]}{\left[H_{2} L^{-}\right]} \text {And } K_{a 3}=\frac{\left[L^{3-} I H^{+}\right]}{\left[H L^{2-}\right]}
\end{aligned}
$$

The expression of the analytical concentration $\mathrm{C}_{\mathrm{L}}$ of citric acid in the solution is given by the formula

$\mathrm{C}_{\mathrm{L}}=\left[\mathrm{L}^{3-}\right]+\left[\mathrm{HL}^{2-}\right]+\left[\mathrm{H}_{2} \mathrm{~L}^{-}\right]+\left[\mathrm{H}_{3} \mathrm{~L}\right]_{\text {free }}=\left[\mathrm{L}^{3-}\right] \times(1+$

$\left.\left[\mathrm{H}^{+}\right] / \mathrm{K}_{\mathrm{a} 3}+\left[\mathrm{H}^{+}\right]^{2} / \mathrm{K}_{\mathrm{a} 3} \times \mathrm{K}_{\mathrm{a} 2}+\left[\mathrm{H}^{+}\right]^{3} / \mathrm{K}_{\mathrm{a} 3} \times \mathrm{K}_{\mathrm{a} 2} \times \mathrm{K}_{\mathrm{a} 1}\right)$

For $\mathrm{pH}$ values between $\mathrm{K}_{\mathrm{a} 2}$ and $\mathrm{K}_{\mathrm{a} 3}$, the ions

\section{$\left[\mathrm{HL}^{2-}\right]\left(\mathrm{OOC}-\mathrm{CH}_{2}-(\mathrm{HOOC})-\mathrm{C}-(\mathrm{OH})-\mathrm{COO}^{-}\right)$}

Predominate in the solution.

So $\mathrm{C}_{\mathrm{L}}=\left[\mathrm{HL}^{2-}\right]=\left[\mathrm{L}^{3-}\right] \times\left[\mathrm{H}^{+}\right] / \mathrm{K}_{\mathrm{a} 3}$

Therefore, the stability constant expressed by equation (1) takes the following expression:

$\mathrm{K}_{\mathrm{xyz}}=\left\{[(3,2, \mathrm{z})] /\left[\mathrm{Gd}^{3+}\right]^{3}\left(\mathrm{C}_{\mathrm{L}}\right)^{2}\right\}\left(\mathrm{K}_{\mathrm{a} 3}\right)^{2} \times\left[\mathrm{H}^{+}\right]^{\mathrm{z}-2}$

And the equation (2) become : $\mathrm{K}_{\mathrm{xyz}}=\mathrm{K}{ }_{\mathrm{xyz}} \times\left[\mathrm{H}^{+}\right]^{-(\mathrm{z}-2)} \times \mathrm{K}_{\mathrm{a} 3}{ }^{-2}$

So $\log K_{x y z}^{\prime}=\log K_{x y z}-2 \mathrm{pK}_{\mathrm{a} 3}-(\mathrm{z}-2) \mathrm{pH}$

In the first stage of the characterization of the gadolinium complexes with studied acids, we determined the compositions $\mathrm{x}$, $\mathrm{y}, \mathrm{z}$ and stabilities constants of these colorless complexes. The complexation of the ligands (acids) can be studied using a spectrophotometric method. Since the reagents (acids) and their gadolinium complexes don't possess a characteristic UV-visible absorption spectrum, a second ligand (called the sacrificial ligand) is introduced, this ligand must absorb in the UV-visible spectrum and form a colored complex with gadolinium (III). The dissociation of this colored complex has to cause large variations in the UV-visible spectrum which allows for the calculation of the concentration of the sacrificial complex ; using the formation constant of this colored complex, the concentration of the unknown complex can be obtained. Therefore, the sacrificial ligand must form a single colored complex of lower stability than the gadolinium complex under study. In this work, Sulfo-3"-dichloro-2",6"dimethyl-3,3'-hy doxy-4'-fuchsone-5,5'-dicarboxylic acid, often called Chrome Azurol S and notable $\mathrm{H}_{4} \mathrm{Ch}$, has been used as sacrificial ligand. Chrome Azurol $\mathrm{S}$ is a tetraprotic acid with $\mathrm{pKa}$ values of $2.25\left(\mathrm{H}_{3} \mathrm{Ch}^{-} /\left(\mathrm{H}_{2} \mathrm{Ch}^{-}\right), 4.71\left(\mathrm{H}_{2} \mathrm{Ch}^{2-} / \mathrm{HCh}^{3-}\right)\right.$ and 11.82 $\left(\mathrm{HCh}^{3-} / \mathrm{Ch}_{4}^{-}\right)$(Langmyhr \& Klausen 1963 p. 149). In the experimental pH range (5.50-7.50), the formation of $\mathrm{H}_{4} \mathrm{Ch}, \mathrm{H}_{3} \mathrm{Ch}^{-}$and $\mathrm{H}_{2} \mathrm{Ch}^{2-}$ has been neglected. It is an indicator which is generally used for the photometric proportioning of the metal ions in solution (Dona \& Verchere 1991 p. 533). In this work the interaction of the $\mathrm{H}_{4} \mathrm{Ch}$ with gadolinium ions $\left(\mathrm{Gd}^{3+}\right)$, gives a colored reagent ( $\lambda_{\text {max }}=545 \mathrm{~nm}$ ) of average stability for values of $\mathrm{pH}$ ranging between 5.50 and 7.50. The buffer "MESH", [2-(N-Morpholino) sulfonic ethane acid] was adopted to fix $\mathrm{pH}$ in the study of the sacrificial complex (Gadolinium- $\mathrm{H}_{4} \mathrm{Ch}$ ) and gadolinium-Ligands (complexes studied in this work). We chose this buffer because it does not present any interaction with $\mathrm{Gd}^{3+}$ ions and so we would be able to work in the range of $\mathrm{pH}$ where the stability of the sacrificial complex is maximal.

\subsection{Formation of the colored sacrificial complex $G d_{x}(H C h)$}

The majority of organometallic complexes studied are colorless. Thus the study of the formation of the sacrificial complex $G d_{x}(H C h)_{y}$ is very important, because this steps decisive parameters (composition and stability) of gadolinic complexes charactirazed in this work. In this sense, we have demonstrated, experimentally, that the composition and stability of the colored sacrificial complex (Gd-CAS) were determined, we found a complex type $(3,2,3)$ and stability constant $\log K_{323}=16.27$ in $\mathrm{pH}$ range 5.50-7.50 (Ramshing et al. 1980 p. 165, Verchere \&, Dona 1992 p. 437, Morin et al. 1994 p. 178, Hlaïbi et al. 2009 p. 310), the equilibrium reaction for this complex is

$$
3 \mathrm{Gd}^{3+}+2 \mathrm{HCh}^{3-}+3 \mathrm{H}^{+} \rightleftarrows(3,2,3)+\mathrm{nH}_{2} \mathrm{O}
$$

We use these results of sacrificial complex formed in solution, to study two colouress complexes Gd-Citrate ions and $\mathrm{Gd}-$ camphorate ions.

\subsection{Composition and stability of the Gd (III) - Acids}

The ligands (acids) are added separated to a colored solution containing sacrificial complex $\mathrm{Gd}_{3} \mathrm{HCh}_{2}$, this complex will dissociate under effect of these ligands. To calculate the complex concentration of the $\mathrm{HCh}^{3-}$ ions, the absorption values of the totally complexed $\left(\mathrm{A}_{\mathrm{F}}\right)$, and the completely dissociated $\left(\mathrm{A}_{\mathrm{I}}\right) H C h^{3-}$ ions have to be determined. Then the following equations can be used :

$$
[(x, y, z)]=\alpha \times C_{L}=C_{L} \cdot\left(A-A_{I}\right) /\left(A_{F}-A_{I}\right)
$$

$\alpha$ coefficient of sacrificial complex formation.

$$
\left[H C h^{3-}\right]_{\text {ree }}=C_{L} \times\left(A_{F}-A\right) /\left(A_{F}-A_{I}\right)
$$

When the conditional constant $\mathrm{K}^{\prime}{ }_{323}$ of the sacrificial complex is known, the concentration of free gadolinium ion $\left(\left[G d^{3+}\right]\right)$, can be calculated using Equations (7) and (8). Knowing the two concentrations of complex $[(3,2,3)]$ and of $\left[G d^{3+}\right]$, the concentration of the gadolinium complex under study $[(\mathrm{x}, \mathrm{y}, \mathrm{z})]$ (balanced reaction I) can be determined using the gadolinium balance equation :

$x \cdot[(x, y, z)]=C_{G d}-\left[G d^{3+}\right]_{\text {rree }}-3[(3,2,3)]$

$\mathrm{C}_{\mathrm{Gd}}$ the initial gadolinium concentration and $[(\mathrm{x}, \mathrm{y}, \mathrm{z})]$ the concentration of coloress complex formed.

In a similar way, the concentration of the free ligand is obtained by Eq. (10) :

$\left(C_{L^{n-}}\right)_{\text {free }}=\left(C_{L^{n-}}\right)_{\text {initial }}-y\left[\left(\begin{array}{lll}x & y, z\end{array}\right)\right]$

It should be also noted that a perfect knowledge of the characteristics of the sacrificial colored complex $\left(\mathrm{Gd}_{3} \mathrm{HCh}_{2}\right)$ is necessary. The determination of the composition and the stability of the sacrificial complex and the precision of the conditions of its formation are paramount stages to apply the indirect photometry detection. In each experiment, the ligands completely deprotonate are added stepwise in order to measure the absorption at different values of the overall initial concentration of these studied ligands. The correct $K_{x y z}^{\prime}$ looked for by varying $\mathrm{X}$ and $\mathrm{Y}$ in order to obtain a constant value of $K_{x y z}^{\prime}$ for all values of $C_{L^{n-}}$ added in solution. If $\log K_{x y z}$ is determined at different $\mathrm{pH}$, the slope of the $\log K_{x y z}^{\prime}=f(p H)$ plot reveals the number $\mathrm{z}$ of protons that is very necessary for the formation of the studied gadolinium complexes by the use of Eq. (5), since the value of $K_{x y z}$ is independent of $\mathrm{pH}$. 


\subsection{Determination of the composition and the stability constant of complexes Gd-Acids}

With an aim of determining the composition and the stability constant of the gadolinium-citrate ions and gadolinium-Camphorate ions, we monitoring the evolution of the absorbance during the disappearance of the sacrificial complex by the addition of increasing quantities of ligands. For a given volume $(50 \mathrm{~mL})$ of a solution containing sacrificial complex $(3,2,3)\left(10^{-4} \mathrm{M}\right)$, we added increasing quantities of $\mathrm{L}^{3-}$ and $\mathrm{L}^{2-}$ ions with known concentration. The spectrophotometric study carried out with fixed wave- length ( $\lambda_{\max }=545 \mathrm{~nm}$ ), showed a reduction in the absorbance of the solution progressively with the addition of the acids (figure 1). The dissociation of the sacrificial complex, relating to the reduction in the absorbance by the addition of ligands, is done in favor of the formation of the colorless complex between $\mathrm{Gd}^{3+}$ and studied acids. The curves $\mathrm{C} 1$ and $\mathrm{C} 2$, in figure 1, of complexes formed in solution $\mathrm{Gd}-\mathrm{H}_{3} \mathrm{~L}$ and $\mathrm{Gd}-\mathrm{H}_{2} \mathrm{~L}$ respectively, clearly show that the absorbance decreases and stabilizes. This stability indicates that all $G d^{3+}$ ions, initially present in the solution have reacted with ligands.

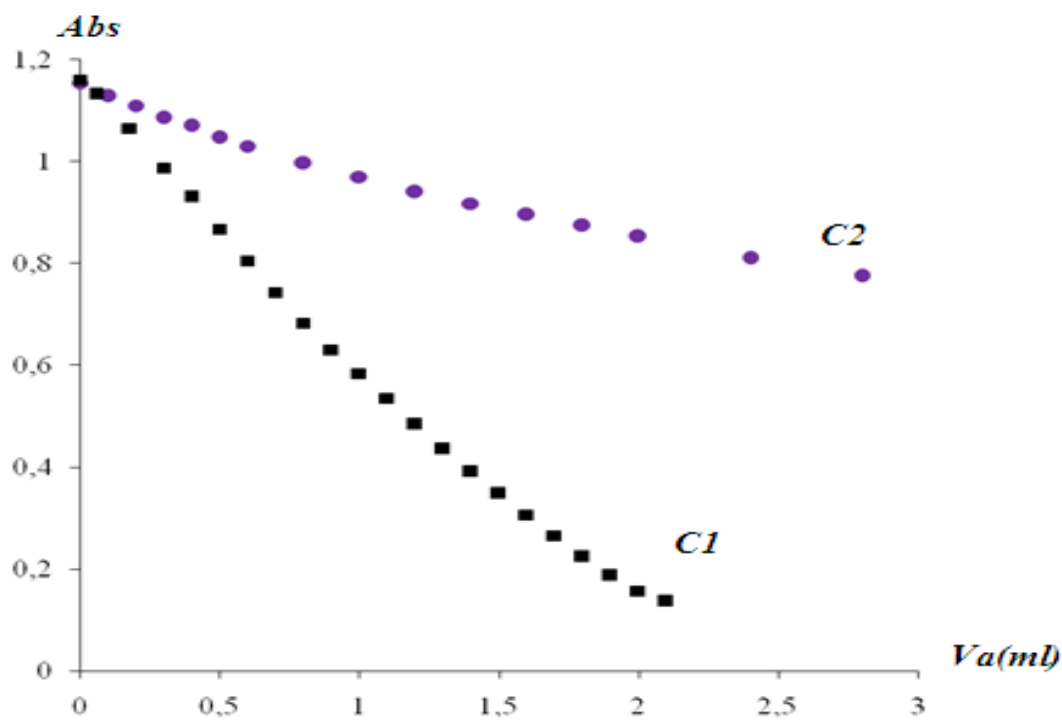

Fig. 1: Decomposition of Colored Sacrificial Complex by Addition of $\mathrm{H}_{3} \mathrm{~L}$ and $\mathrm{H}_{2} \mathrm{~L}$ Ions.

$C 1: \mathrm{Gd}-\mathrm{H}_{3} \mathrm{~L}$, Mass concentration $1 \mathrm{~g} / \mathrm{L}, \mathrm{pH}=6,46$ and $C 2: \mathrm{Gd}-\mathrm{H}_{2} \mathrm{~L}$, Mass concentration $10 \mathrm{~g} / L, \mathrm{pH}=6,27$

Knowing the concentration of gadolinium ions and the quantity of ligands (added volume Va of acid), necessary to reach this stage of absorption, we could determine the molar ratio $q=\left(\left[G d^{3+}\right] /[\right.$ acid $\left.]\right)$, involved in the complexation reaction. The preceding experiment was carried out for different values of $\mathrm{pH}$ between 5.50 and 7.50, the way in which the absorption decreases, depends on the $\mathrm{pH}$ of the medium and on the formation constant of the detected complexes, as well as on the absorption values $\left(\mathrm{A}_{\mathrm{I}}\right)$ and $\left(A_{F}\right)$ of the free and totally complexed Chrome Azurol S. Analyzing the experimental data with the computer program written from the balanced reaction (I), the results confirm the reproduci- bility of the molar ratio $q=\left(\left[G d^{3+}\right] /[\right.$ acid $\left.]\right)=x / y$ and to determine the composition and the stability constant $K_{x x z}^{\prime}$. This program is not a theoretical modeling (but this is a translation of the reaction steps of the balance (I) for ease of calculation). In figure 2 we represent an example of calculating the ratio $\mathrm{q}$ at $\mathrm{pH} 6.46$ of complex Gd- $\mathrm{H}_{3} \mathrm{~L}$, where we inserted the two experimental values: $V_{a}$ and Abs corresponds for each added volume $V_{a}$ of ligand, to seek the values of $\mathrm{X}$ and $\mathrm{Y}$ to the value of $\log K_{x y z}^{\prime}$ which remains constant.

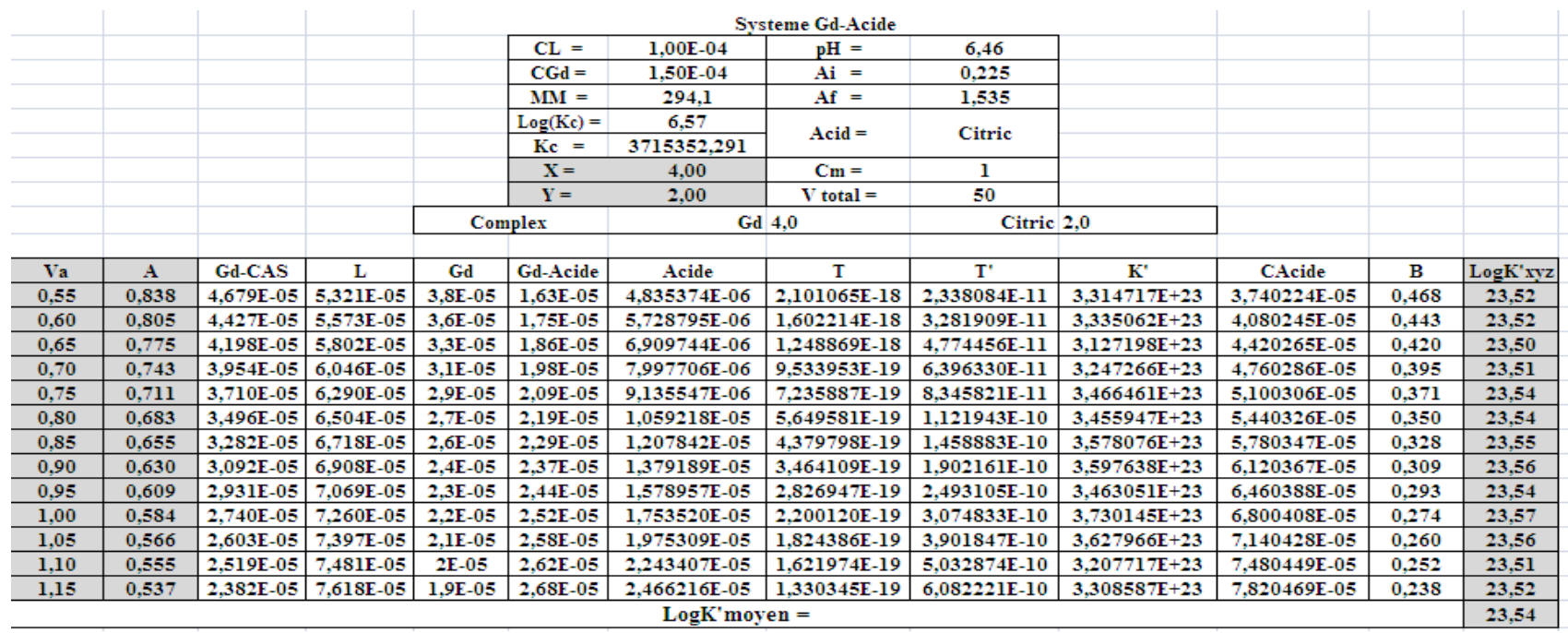

Fig. 2: Example of Program Used to Calculate the Compositions X, Y and Stability $\log K_{x z}^{\prime}$.

$C_{m}$ : Mass concentration $(1 g / L), V_{a}$ : volume of acid, A =Abs experimental absorbance, $K c$ : constant of colored sacrificial complex, $\log K_{x z 2}^{\prime}$ moy $=23,54$ for $q=x / y=4 / 2$ and $p H=6.46$ 
The calculations are repeated for different experimental values of $\mathrm{pH}$ between 5.50 and 7.50. We obtained a molar ratio $q=x / y$ for Gd- $\mathrm{H}_{3} \mathrm{~L}$ equal 4:2 and 2:2 for $\mathrm{H}_{2} \mathrm{~L}$. The data-processing treatment of the preceding experimental results, shows that these di and tetra-nuclear complexes are formed between the gadolinium ions and ligands, resulting from the interaction of two Gd (III) ions equivalents with two equivalents of $\mathrm{H}_{2} \mathrm{~L}$ and four $\mathrm{Gd}$ (III) ions for $\mathrm{H}_{3} \mathrm{~L}$, so a molar ratio $\mathrm{q}$ and conditional constant $\log K_{x y z}^{\prime}$ remains the same for each fixed value of $\mathrm{pH}$ between 5.50 and 7.50 for two complexes formed. The constants and the molar ratio $\mathrm{q}$ at differents values of $\mathrm{pH}$ are given in Table 2 .

Table II: The Conditional Stability of the Two Complexes Detected

\begin{tabular}{|c|c|c|c|c|c|c|c|}
\hline \multirow{2}{*}{$\mathrm{Gd}-\mathrm{H}_{3} \mathrm{~L}$} & $\mathrm{pH}$ & 5.50 & 5.63 & 5.83 & 6.02 & 6.24 & 6.46 \\
\hline & $\log K_{42 z}$ & 26.00 & 25.70 & 24.99 & 24.48 & 24.08 & 24.53 \\
\hline \multirow{2}{*}{$\mathrm{Gd}-\mathrm{H}_{2} \mathrm{~L}$} & $\mathrm{pH}$ & ------ & 5.62 & 5.85 & 6.07 & 6.27 & 6.50 \\
\hline & $\log K_{22 z}^{\prime}$ & ------ & 11.62 & 11.14 & 10.69 & 10.28 & 9.82 \\
\hline
\end{tabular}

Buffer $\left(\mathrm{MES}^{-} / \mathrm{MESH}\right), \lambda_{\max }=545 \mathrm{~nm}, l=1 \mathrm{~cm},\left[\mathrm{HCh}^{3-}\right]_{\text {otal }}=10^{-4} \mathrm{M}$

Therefore, for the complexation reaction, results of $\log K_{x y z}$, the reactions (I) and (II) and the equtions (1), (2), (5) and (6) allow us to write the following expressions for each complex:

\subsection{1. $\mathrm{Gd}-\mathrm{H}_{3} \mathrm{~L}$}

$$
\begin{aligned}
& 4 G d^{3+}+2 L^{3-}+z H^{+} \rightleftarrows(4,2, z)+n H_{2} \mathrm{O} \\
& K_{42 z}=[(4,2, z)] /\left(\left[G d^{3+}\right]^{4} \cdot\left(\mathrm{C}_{L}\right)^{2}\right)
\end{aligned}
$$

So, $\log \mathrm{K}_{42 z}^{\prime}=\log \mathrm{K}_{42 z}-2 \mathrm{pK}_{a 3}-(\mathrm{z}-2) \mathrm{pH}$

\subsection{2. $\mathbf{G d}-\mathrm{H}_{2} \mathrm{~L}$}

$$
\begin{aligned}
& 2 G d^{3+}+2 L^{2-}+z H^{+} \rightleftarrows(2,2, z)+n H_{2} O \\
& K_{22 z}^{\prime}=\left[(2,2, z] /\left(\left[G d^{3+}\right]^{2} \cdot\left[L^{2-}\right]^{2}\right)=K_{22 z} \times\left[H^{+}\right]\right.
\end{aligned}
$$

And $\log K_{22 z}=\log K_{22 z}-$ z.pH

For two complexes detected, the results in table 2 combined with equations (12) and (14) allow to plot functions $\log K_{x y z}^{\prime}=f(p H)$ for two complexes formed, hence determine the number $\mathrm{z}$ of protons $\mathrm{H}^{+}$involved in the reaction obtained from the straight lines. The evolution of $\log K_{x y z}^{\prime}$ at different $\mathrm{pH}$ values represented in figure 3.

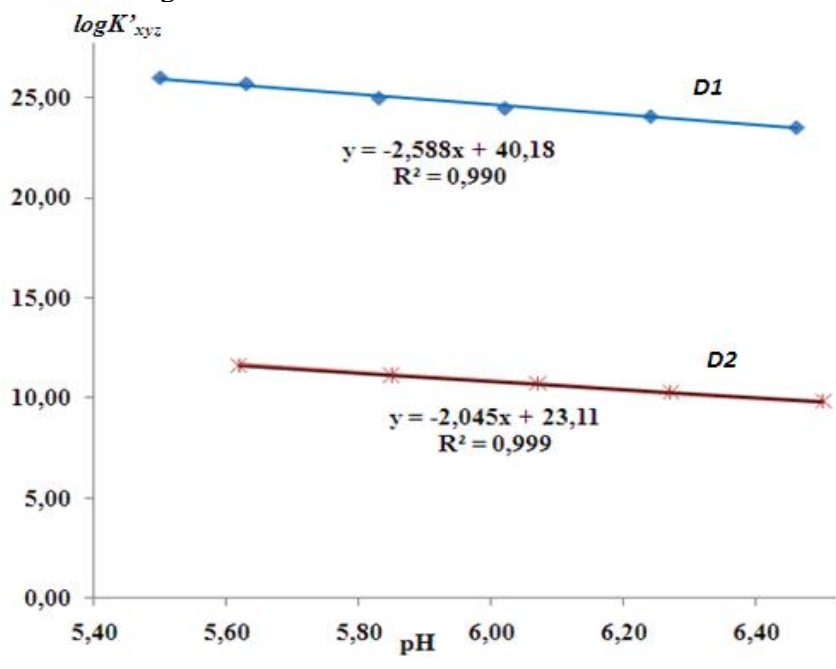

Fig. 3: The Evolution of $\log K_{x y z}^{\prime}$ at Different $\mathrm{pH}$ Values.

D1: $\log K^{\prime}{ }_{42 z}=\mathrm{f}(\mathrm{pH})$ of Complex $\mathrm{Gd}-\mathrm{H}_{3} \mathrm{~L}$ and D2: $\log K^{\prime}{ }_{22 z}=\mathrm{f}$ (pH) of Complex $\mathrm{Gd}-\mathrm{H}_{2} \mathrm{~L}$
This evolution of $\log K_{x y z}^{\prime}=\mathrm{f}(\mathrm{pH})$ is linear and the slope $\mathrm{p}$ of the straight line is equal to $\approx-5 / 2$ for complex $\mathrm{Gd}-\mathrm{H}_{3} \mathrm{~L}$ and -2 for complex Gd- $\mathrm{H}_{2} \mathrm{~L}$. So, the value of $-(z-2)=p \approx-5 / 2 \Leftrightarrow z=9 / 2$ for $\mathrm{Gd}-\mathrm{H}_{3} \mathrm{~L}$ and for $\mathrm{Gd}-\mathrm{H}_{2} \mathrm{~L}-z=p=-2 \Leftrightarrow z=2$ represents the number of protons $\mathrm{H}^{+}$involved in the formation of two complexes respectively. The Equations (12) and (14) allowed us to calculate the stability constants $\log K_{x z z}$ for theses two complexes, the experimental results obtained by the IPD are $\log K_{42(9 / 2)}-2 p K_{a 3}=40.18 \pm 0.01 \quad$ with $\mathrm{pK}_{\mathrm{a} 3}=6.50$, so $\log K_{42(9 / 2)}=53.18 \pm 0.01 \quad\left(\quad K_{42(9 / 2)}=1,514.10^{53} \quad\right) \quad$ and $\log K_{222}=23.11 \pm 0.01 \quad\left(K_{222}=1,288.10^{23}\right)$ for $\mathrm{Gd}-\mathrm{H}_{3} \mathrm{~L}$ and $\mathrm{Gd}-\mathrm{H}_{2} \mathrm{~L}$ respectively.

Consequently, the spectrophotometric results concerning the interaction of the $\mathrm{Gd}(\mathrm{III})$ ion with $\mathrm{H}_{2} \mathrm{~L}$ show that the complexation reaction uses two Gd(III) ions, two carboxylates and fixation of two $\mathrm{H}^{+}$protons, but in the case of complex $\mathrm{Gd}-\mathrm{H}_{3} \mathrm{~L}$, there are four Gd(III) ions interact with two ligands and the intervention of $9 / 2 \mathrm{H}^{+}$. So, by comparing with other works on the complexes of the gadolinium ion (Hlaibi et al. 2009 p. 310, Riri et al. 2014 p. 130 , Riri et 2016 p. 1478), we have given the general formulas of these two complexes Gd-Citrate and Gd-Camphorate, therefore the both formulas are $\mathrm{Gd}_{4}$ Citrate $_{2} \cdot 4 \mathrm{NO}_{3} \cdot \mathrm{nH}_{2} \mathrm{O}$ and $\mathrm{Gd}_{2}$ Camphorate $2.2 \mathrm{NO}_{3} \cdot \mathrm{mH}_{2} \mathrm{O}$.

Finally, we have obtained one dinuclear complex type $(2,2,2)$ for camphoric acid in $\mathrm{pH}$ range $5.50-7.50$, and one tetranuclear complex type $(4,2,9 / 2)$ for the complex Gd-Citric acid in 5.50 $<\mathrm{pH}<6.50$; but for $\mathrm{pH}$ values between 6.50 and 7.50 the study of the formation of complex Gd-Citric acid is not treated in this work.

\section{Conclusion}

In this work, we have identified and characterized two new polynuclear and plydentate complexes of gadolinium ion in aqueous solutions and in a pH region 5.50 to 7.50 , using the indirect photometry detection. This technique was used successfully to determining the composition, and the stability of these major complexes formed in very dilute sulution, so we obtained two types of composition $(2,2,2)$ for complex $\mathrm{Gd}-\mathrm{H}_{2} \mathrm{~L}$ and $(4,2,9 / 2) 2,9 / 2$ for complex $\mathrm{Gd}-\mathrm{H}_{3} \mathrm{~L}$. The stabilities of these new godolinium complexes are $\log K_{42(9 / 2)}=53.18 \pm 0.01$ and $\log K_{222}=23.11 \pm 0.01$ for $\mathrm{Gd}-$ $\mathrm{H}_{3} \mathrm{~L}$ and $\mathrm{Gd}-\mathrm{H}_{2} \mathrm{~L}$ respectively. We also mentioned that the acidity of the medium has a very important in determining the nature of the chelation site formed: bidentate and tetradentate (Hlaibi et al. 2009 p. 310, Riri et 2016 p. 1478).

\section{References}

[1] Reimer P, Tombach B, Heike D, Hesse T, Sander G, Balzer T, Shamsi K, Berns T, Rummeny E J, Peters P E (1996) Neue MRKontrastmittel in der Leberdiagnostik Erste klinische Ergebnisse mit hepatobiliärem Eovist ${ }^{\circledR}$ (Gadolinium-EOB-DTPA) und RESspezifischem Resovist (SH U 555 A). Der Radiologe 36, 124-133. https://doi.org/10.1007/s001170050049.

[2] Thunus L, Lejeune, R (1999) Overview of transition metal and lanthanide complexes as diagnostic tools. Coordination Chemistry Reviews 184, 125-155 https://doi.org/10.1016/S0010-8545(98)002069 .

[3] Guo-Ping Y, Mai-Li L, Li-Yun L (2005) Studies on polyaspartamide gadolinium complexes as potential magnetic resonance imaging contrast agents. Radiography 11, 117-122 https://doi.org/10.1016/i.radi.2004.12.006.

[4] Yoshimasa M, Masashi I, Natsuki K, Hsien-Han L, Taro A, Chizuko IY, Yuki M, Yoshichika Y, Yoshitomo H, Shoko G (2016) Mono- and dinuclear gadolinium(III) complexes of tris (4-carboxy-3benzyl-3-azabutyl) amine: Synthesis and relaxation properties. $\mathrm{Po}$ lyhedron 107, 148-152 https://doi.org/10.1016/i.poly.2015.12.064. 
[5] Sofía M, Martín G B (2017) Synthesis of Gadolinium-based Nanos tructures Through an Enzymatic Liposome-controlled Reaction. Colloid and Interface Science Communications 19, 31-34.

[6] Rocklin R D (1991) Detection in ion chromatography. J, Chromatogr. 546, 175-187. https://doi.org/10.1016/S0021-9673(01)93016$\underline{\mathrm{X}}$.

[7] Verchere J F, Dona A M, (1992) Exchange methods for the indirect photometric determination of anions and organic molecules. Analusis $20,437-450 \mathrm{~N}^{\circ}$ notice refdoc (ud4) : 4321863.

[8] Morin P, François C, Dreux M (1994) Séparation de cations et d'anions inorganiques par éléctrophorèse capillaire ionique avec une détection spectrométrique UV indirecte, Capillary electrophoresis of inorganic cations and anions with different carrier electrolytes and UV detection. Analusis 22, 178-187 $\mathrm{N}^{\circ}$ notice refdoc (ud4) : 4091847.

[9] Ramshing A, Rusika J, Hasen E H (1980) A new approach to enzymatic assay based on flow-injection spectrophotometry with acid-base indicators. Anal. Chim. Acta 114, 165-181 https://doi.org/10.1016/S0003-2670(01)84288-4.

[10] Riri M, Benjjar A, Kamal O, Hor M, Touaj K, Hlaibi M (2014) Novel gadolinium complexes in aqueous solution : characterization, identification and probable structures. International Journal of Ad$\begin{array}{llll}\text { vanced } & \text { Chemistry } & \text { 130-138 }\end{array}$ https://doi.org/10.14419/ijac.v2i2.2926.

[11] Hlaïbi M, Hor M, Riri M, Benjjar A, Verchère J F (2009) Mult in uclear $183 \mathrm{~W}$ and 13C NMR and indirect photometry study for the identification and the characterization of new complexes of sugar acids. J. of Molecular Structure 920, 310-322 https://doi.org/10.1016/j.molstruc.2008.11.016.

[12] Riri M, Hor M, Kamal O, Eljaddi T, Benjjar A, Hlaıbi, M (2011) New gadolinium(III) complexes with simple organic acids (Oxalic, Glycolic and Malic Acid), Journal of Materials \& Environmenta Science 2, 303-308.

[13] Riri M, Kamal O, Benjjar A, Serdaoui F, Hlaibi M (2013) Composition, Stability and Probable Structure of a Colourless Organometallic Complex (Gd(III)-Malic Acid). Open Journal of $\begin{array}{llll}\text { Physical Chemistry } & 3, & 49-58\end{array}$ https://doi.org/10.4236/ojpc. 2013.31007

[14] Millan M M, Jon S B, Richard J W,Peter C F (1995) Synthesis, Structure, and Spectroscopic Properties of Ortho-Metalated Platinum(II) Complexes. Inorg. Chem. 34, 2334-2342 https://doi.org/10.1021/ic00113a013.

[15] Nonat A, Gateau C, Fries P H, Mazzanti M (2006) Lanthanide Complexes of a Picolinate Ligand Derived from 1,4,7Triazacyclononane with Potential Application in Magnetic Resonance Imaging and Time-Resolved Luminescence Imaging. Chem. Eur. $\quad$ J. $12, \quad 7133-750$ https://doi.org/10.1002/chem.200501390.

[16] Hiroyuki M, Masaaki W, Makoto T, Takayuki H, Yoshitane K, Michiko B I, Motomichi I, Quint us F (2002) Novel optically-active bis(amino acid) ligands and their complexation with gadolinium. Journal of the Chemical Society, Dalt on Transactions 6, 1119-1125 https://doi.org/10.1039/b108024p.

[17] Anelli P L, Calabi L, De Haen C, Lttuda L, Lorosso V, Maiocchi A, Morosini P, Uggeri F (1997) hepatocyte-directed MRI contras agents - can we take advantage of bile-acids. Acta Radiologica 38 , $125-133$.

[18] Angela P L T, Wing-Tak W (2008) Synthesis, structure, and stability studies of dimeric gadolinium(III) complexes containing cyclic polyaminopolycarboxylic bisamide ligands. Inorganic Chemistry Communications $11, \quad 1323-1326$ https://doi.org/10.1016/i.inoche.2008.08.013

[19] Jonathan M, Beeta B M, Rachael P, Mark F L, Andrew J P W, Patrizia F, Joachim H G S, Ramon V (2010) coordination chemistry of amide-functionalised tetraazamacrocycles: structural, relax ometric and cytotoxicity studies. Dalton Trans. 39, 10056-10067 https://doi.org/10.1039/c0dt00815j.

[20] Moller R P, Sasu K (2010) Gd-DTPA in the hydrosphere: Kinetics of transmetallation by ions of rare earth elements, $\mathrm{Y}$ and $\mathrm{Cu}$. Chemie der $\quad$ Erde. $\quad 70,125-136$ https://doi.org/10.1016/i.chemer.2010.01.003.

[21] Nwe K, Bernardo M, Regino C A S, Williams M, Brechbiel, W M (2010) Comparison of MRI properties between derivatized DTPA and DOTA gadolinium-dendrimer conjugates. Bioorganic Med. Chem. 18, 5925-5931 https://doi.org/10.1016/i.bmc.2010.06.086

[22] Tsan-Hwang C, Yun-Ming W, Kuei-Tang L, Gin-Chung L (2001) Synthesis of four derivatives of 3,6,10-tri(carboxymethyl)-3,6,10triazadodecanedioic acid, the stabilities of their complexes with $\mathrm{Ca}(\mathrm{II}), \mathrm{Cu}(\mathrm{II}), \mathrm{Zn}$ (II) and lanthanide(III) and water-exchange investigations of $\mathrm{Gd}(\mathrm{III})$ chelates. Journal of the Chemi- cal Society, Dalton

Transactions

22

$3357-3366$ https://doi.org/10.1039/b107456n.

[23] Lee A S, Lee HC, Jung Y W, Lee J, Choi W J, Kim A K, Park M C (2011) Paradoxical high signal intensity of hepatocellular carcino$m a$ in the hepatobiliary phase of Gd-EOB-DTPA enhanced MRI: initial experience. Magnetic Resonance Imaging 29, 83-90 https://doi.org/10.1016/i.mri.2010.07.019.

[24] Moller P R, Knappe A, Dulski P, Pekdeger A (2011) Behavior of Gd-DTPA in simulated bank filtration. Applied Geochemistry 26, 140-149. https://doi.org/10.1016/i.apgeochem.2010.11.011.

[25] Kostova I, Momekov G, Stancheva, P (2007) New Samarium (III) Gadolinium (III), and Dysprosium (III) Complexes of Coumarin-3Carboxylic Acid as Antiproliferative Agents. Metal-Based Drugs 2007, 8 https://doi.org/10.1155/2007/15925.

[26] Yue W, Xueyi W, Qingtao M, Hongmin J, Run Z, Peixun Z, Renfeng S, Huan F, Zhiqiang Z (2017) A gadolinium(III)-coumarin complex based MRI/Fluorescence bimodal probe for the detection of fluoride ion in aqueous medium. Tetrahedron 73, 5700-5705 https://doi.org/10.1016/i.tet.2017.08.007.

[27] Elisa S S M, Dina M, Zênis N d R, Ana S P, João G B, Ana M A Mafalda L, João E C-L, Maria F B, Alberto A C C P, Sandra C C N, Hugh D B, Telma C (2017) Dibrominated camphoric acid derived salen complexes: Synthesis, characterization and cytotoxic activity.Polyhedron 137, 147-156.

[28] Huijie L, Jinghe Y, Linyu J, Sasa C, Yanlong B, Xudong Z, Yamin L (2015) Syntheses, structures and properties of two new coordination polymers based on d-camphoric acid and 2-phenyl-4,6diamino-1, 3, 5-triazine. Journal of Solid State Chemistry 225, 135140 https://doi.org/10.1016/j.jssc.2014.12.011.

[29] Soo Y L, Kwang Y L, Hyeon G L (2017) Effect of different pH conditions on the in vitro digestibility and physicochemical properties of citric acid-treated pot ato starch. International Journal of Biological Macromolecules In Press, Accepted Manuscript.

[30] Xuefei L, Yingying W, Huijie L, Haiyan L, Jinghe Y, Yamin L (2017) four isostructural lanthanide coordination polymers based on rare coordinated citric acid: Syntheses, structures, magnetisms and luminescence 232, 103-110

[31] Serjeant P E, Dempsey B (1979) Ionization Constants of Organic Acids in Aqueous Solution (Pergamon, Oxford).

[32] Bjerrum J and al., Stability Constants (1958) Chemical Society, London, United Kinkdom.

[33] Langmyhr J F, Klausen K S, (1963) Complex formation of iron (III) with chrome azurol S. Analytica Chimica Acta 29, 149-167 https://doi.org/10.1016/S0003-2670(00)88596-7.

[34] Dona M A, Verchere F (1991) Analytical applications of oxocarbons. Part 3. Specific spectrophoto-metric determination of oxalic acid by dissociation of the zirconium (IV)-chloranilate complex. Analyst 116, 533-536 https://doi.org/10.1039/AN991 1600533.

[35] Riri M, Hor M, Serdaoui F, Hlaibi M (2016) Complexation of trivalent lanthanide cations by different chelation sites of malic and tartric acid (composition, stability and probable structure). Arabian $\begin{array}{llll}\text { Journal of } & \text { Chemistry } & \text { S1478-S1486 }\end{array}$ https://doi.org/10.1016/i.arabic.2012.03.012. 